\title{
Parents' Attitude Toward Child Abuse Conducted in the Health Centers of Tabriz
}

\author{
Maliheh Asadollahi, ${ }^{1}$ Mahnaz Jabraeili, ${ }^{1}$ Mohammad Asghari Jafarabadi, ${ }^{2}$ and Marzieh Hallaj ${ }^{1,}$ \\ ${ }^{1}$ Department of Nursing, Tabriz University of Medical Sciences, Tabriz, IR Iran \\ ${ }^{2}$ Road Traffic Injury Research Center, Tabriz University of Medical Sciences, Tabriz, IR Iran \\ "Corresponding author: Marzieh Hallaj, Department of Nursing, Tabriz University of Medical Sciences, Tabriz, IR Iran. Tel: +98-4134799151, Fax: +98-4134796969, E-mail: \\ mhmazidluei10@yahoo.com
}

Received 2015 July 01; Revised 2015 August 02; Accepted 2015 August 10.

\begin{abstract}
Background: Attitudes are very important in the formation of behaviors. Parents' attitudes toward children and behaviors with them are the main causes of child abuse. Identifying these attitudes and their related factors can be the primary basic action for prevention of child abuse.

Objectives: This study was conducted to investigate the parents' attitudes toward child abuse in the health centers of Tabriz.

Patients and Methods: In this cross-sectional study 384 parents with children 2 to 12 years old, filled a questionnaire about parents' attitude toward child abuse in the 13 health centers of Tabriz. Data was analyzed using SPSS (version 16.0).

Results: The results showed that the mean score of total attitude toward child abuse was significantly higher than the middle (P $<0.001)$ and was correlated significantly with 'parents' educational level, number of children they have, attendance status and economic status $(\mathrm{P}<0.05)$.

Conclusions: The results showed that the parents' attitudes toward child abuse were negative, but because of the relationship between parents' attitudes with some of their demographic characteristics, parents should be supported economically and socially to prevention of child abuse.
\end{abstract}

Keywords: Parents, Child Abuse, Attitude

\section{Background}

Child abuse as an abnormal and inhuman behavior is a phenomenon that has been identified during the Industrial Revolution gradually and has passed of the middle decades of the century and is widely considered by thinkers from various fields of social, legal, psychological etc. (1). Significantly early child abuse can disturb a child's normal developmental arc and leave the victim with significant long-term health problems (2) and it is one of the most intensive and stressful experience that could affect the child's development (3). Regardless of the features associated with victim child research on perpetrators of child abuse indicate the direct responsibility of parents in more than $78 \%$ of cases (1).

Child abuse may occur in many different causes and parents' attitude is one of the important factors in the occurrence of it. Attitudes are a, a mental state-conscious or unconscious; b, a value, belief, or feeling; and; c, a predisposition to behavior or action. An attitude has a cognitive, affective, and behavioral component. Attitude refers to a condition towards or against a certain phenomenon, person, or thing. This definition provides two aspects of an attitude: a, an attitude is bipolar; it can be positive or nega- tive, desirable or undesirable and b, an attitude is a reaction to a person, object, or situation (4).

Parental attitudes belong to key social roles in society. These attitudes are gender-specific but also have elements that are common for both parents (5). Studies have shown that parents, who have attitudes that devalue children and who have positive attitude toward child abuse than who have a negative attitude, are more committed child abuse (6-10). The number of studies about parents' attitude toward child abuse is very low and these studies investigated parents' attitude toward physical abuse and physical punishment in the most cases and other aspects of it have been less investigated. Considering that the primary prevention emphasis on prevention of disease and the occurrence of undesirable events by eliminating risk factors and enhancement the quality of life in all its dimensions (11), study of parental attitudes toward child abuse can be used as primary prevention to identification the prone abuse parents and prevention of child abuse.

\section{Objectives}

This study aimed to determine parents' attitudes toward child abuse and the impact of parents' demographic 
characteristics on their attitudes, in order to prevention the abuse of children by their parents.

\section{Patients and Methods}

\subsection{Study Design and Participants}

In this cross-sectional investigation, study population was all parents with children aged 2 - 12 referred to health centers in Tabriz in 2014. The sample size was calculated 384 based on Morgan Table with 95\% confidence and 5\% acceptable margin of error. The sampling was multi-stage: Firstly the ten districts of Tabriz were selected as a category, secondly 13 health centers were randomly selected from these districts depending on number of health center in each district as clusters, and thirdly the sampling was carried out on convenient and eligible participants. The number of parents in each health center was allocated in proportion to the number of all cases referring to there. The inclusion criteria included: a desire to participate in the study, having 2 to 12 years old child, and exclusion criteria included: Not filling in more than $10 \%$ of a questionnaire.

\subsection{Data Collection}

The data was collected through questionnaires including demographic characteristics of parents and 30 attitudinal items about child abuse (physical, emotional and neglect). Parents' attitudes were measured with 10 items in any types of child abuse. It was scored using the Likert scale. Phrases with a negative attitude were rated as followings:

Strongly agree: 5, agree: 4, I cannot give a definitive opinion: 3 , disagree: 2 , and strongly disagree: 1 . The scoring was reversed in phrases with a positive attitude.

A negative attitude toward child abuse means not favoring it. The attitude scores were determined in any kind of child abuse separately from 10 to 50 . So, any score higher than 30 means a negative attitude toward child abuse in that type. Total attitude score was from 30 to 150 and the score higher than 90 indicated a negative attitude toward child abuse.

To determine the validity, the questionnaire was given to ten professors of the university and their views were applied to improve it. Reliability was calculated determining the cronbach's alpha coefficient which was 0.85 for the total items, 0.72 for physical child abuse, 0.82 for emotional child abuse, and 0.75 for neglect in a pilot study.

\subsection{Data Analysis}

After the data collection, the analysis and comparison of mean values were done using SPSS version 16.0 and descriptive statistics, One-Sample t-test, Independent Sample t-test, Pearson correlation coefficient and ANOVA with post hoc tests in $\mathrm{P}<0.05$ and considering standard error (SE).

\subsection{Ethical Considerations}

This study conducted obtaining permission from research council of the Tabriz University of Medical Sciences, the faculty of nursing and midwifery and the ethics committee of Tabriz University of Medical Sciences. Also permission was obtained from the administrators of the health centers. All participants who were eligible for the study, recruited after explaining the purpose and importance of the study, not to mention the names, participants' information confidentiality and with the consent of themselves.

\section{Results}

384 parents completed the questionnaire. The mean age of the participants was $31.72 \pm 6.87$ years. $45.5 \%$ of participants with a maximum number had high school education, \% 37.2 were employed that $83.6 \%$ of them were fathers, $54.5 \%$ had one child, $86.5 \%$ of parents were satisfied with their parents' behavior in the childhood and $67.3 \%$ of them had moderate financial situation.

The mean and standard deviation of parents' attitudes toward child abuse is presented in Table 1 .

Table 1. The Mean Score and Standard Deviation of Parents' Attitudes Toward Child Abuse

\begin{tabular}{lcc}
\hline Attitude Toward Child Abuse & Mean \pm S.D. & Range \\
\hline Physical & $39.21 \pm 5.36$ & $15-50$ \\
Emotional & $38.94 \pm 4.25$ & $26-50$ \\
Neglect & $44.36 \pm 4.17$ & $26-50$ \\
Total & $122.73 \pm 11.38$ & $76-150$ \\
\hline
\end{tabular}

The results comparison mean of the attitude in any type of child abuse with middle numbers are presented in Table 2 shows that the mean score of the attitude in each types of child abuse was significantly higher than the middle number $30,(\mathrm{P}<0.001)$ that represents parents' negative attitude toward child abuse in the three types. Also the mean score of the total attitude was significantly higher than the middle number $90,(\mathrm{P}<0.001)$, that indicates parents have negative attitude toward child abuse.

The results of statistical analysis to investigate the relationship between parents' demographic characteristics and their attitude were as following: 
Table 2. Comparison Between the Mean Score of the Parents' Attitude With 30 and 90 (Middle Numbers) for Each Kind of Child Abuse and the Total Attitude (N = 384$)^{\mathrm{a}, \mathrm{b}}$

\begin{tabular}{|c|c|c|c|}
\hline Attitude Toward Child Abuse & Mean & Mean Difference (CI) & PValue $^{c}$ \\
\hline Physical & 39.21 & $9.21(8.70-9.75)$ & $\mathrm{P}<0.001$ \\
\hline Emotional & 38.94 & $8.94(8.52-9.73)$ & $\mathrm{P}<0.001$ \\
\hline Neglect & 44.36 & $14.36(13.94-14.80)$ & $\mathrm{P}<0.001$ \\
\hline Total & 122.73 & $32.73(31.59-33.88)$ & $\mathrm{P}<0.001$ \\
\hline
\end{tabular}

There was not significant relationship between parents' age, gender, satisfaction of parents, employment status and child gender with mean score of the attitude in three types of child abuse or the total attitude $(P>0.05)$.

On the impact of the parents' attendance status on their attitude, results showed that there was not significant relationship between the mean score of the physical child abuse, emotional child abuse and the mean score of total attitude with attendance status $(\mathrm{P}>0.05)$, but there was a significant relationship between the mean score of the attitude to neglect with attendance status ( $P$ $<0.05)$.This means participants who were single parents, had more positive attitude toward child abuse in neglect.

The results comparison between the mean score of the parents' attitude with their educational levels are presented in Tables 3 and 4 has indicated that there was a significant relationship between the mean score of the physical child abuse, emotional child abuse, neglect and the mean score of the total attitude with educational levels ( $P$ $<0.05)$. This suggests that parents, who had higher educational levels, also had more negative attitudes toward child abuse.

Survey on the effect of the number of children on parents' attitude revealed that there was not significant relationship between the mean score of the emotional child abuse, neglect and the mean score of total attitude with the number of children $(P>0.05)$. However mean score of the physical child abuse was different significantly with the number of children they have $(\mathrm{P}<0.05)$. The difference was between parents with one child and two children that indicated parents who had a child, had more negative attitudes than who had two children in the physical child abuse.

The results of the survey in the relationship between parental attitude and income status revealed that there was not significant relationship between the mean score of the physical child abuse, emotional child abuse and the mean score of total attitude with income status $(P>0.05)$; but there was significant different in the mean score of at- titude toward neglect per parents' income $(\mathrm{P}<0.05)$. The variation was between good and excellent financial situation with the moderate financial situation that reflected parents who had good and excellent economic status, had more negative attitude toward neglect than parents who had moderate financial situation.

Finally $40.3 \%$ of parents agreed that children should be obedient to all the orders of their parents exactly and $54.3 \%$ of them believed that threatening children to a various punishment is not harmful for them.

\section{Discussion}

The findings of this study showed that parents' attitudes toward child abuse and behaviors tend to harassment, were negative and they were disagreed with all types of child abuse. Agha Bakhshi et al., (2005) in a study which investigate the mothers' knowledge, attitude and practice about child abuse, evaluated mothers' attitude as moderate (12). In the present study, the majority of parents disagreed with their children's work and beating children. Consistent with these results, findings of a study by Park (2001) showed except in specific situations mothers reported negative attitudes toward the use of physical punishment totally (7). Our results were not consistent with the findings of a study by Nuhu and Nuhu (2010) that showed parents had positive attitude to some of the physical abuse and agreed to beat children and $34.2 \%$ of parents believed that children should work before given their basic needs and feeding (13). Differences in cultural context and demographic characteristics between parents in two societies can be responsible for the difference in results. As mentioned in the results section, some of the demographic characteristics can influence on the parents' attitudes toward child abuse; for example education levels and parents' income. These demographic characteristics are different in two societies and likely can cause difference in the two communities. Also in the study of Nuhu and Nuhu the results showed that older parents with lower 


\begin{tabular}{|c|c|c|}
\hline Attitude Toward Child Abuse (Educational Levels) & Mean \pm SD & PValue \\
\hline Physical & & $\mathrm{P}<0.001$ \\
\hline Elementary & $35.37 \pm 8.43$ & \\
\hline Guidance school & $37.10 \pm 5.57)$ & \\
\hline High school & $39.09 \pm 4.77$ & \\
\hline Associate's degree & $41.11 \pm 3.79$ & \\
\hline Bachelor's degree or higher & $41.63 \pm 4.13$ & \\
\hline Emotional & & $\mathrm{P}<0.001$ \\
\hline Elementary & $35.87 \pm 4.61$ & \\
\hline Guidance school & $37.98 \pm 4.45$ & \\
\hline High school & $38.91 \pm 3.98$ & \\
\hline Associate's degree & $40.09 \pm 3.35$ & \\
\hline Bachelor's degree or higher & $40.35 \pm 4.26$ & \\
\hline Neglect & & $\mathrm{P}<0.001$ \\
\hline Elementary & $41.07 \pm 5.81$ & \\
\hline Guidance school & $44.51 \pm 3.56$ & \\
\hline High school & $44.25 \pm 4.12$ & \\
\hline Associate's degree & $44.98 \pm 4.08$ & \\
\hline Bachelor's degree or higher & $45.55 \pm 3.28$ & \\
\hline Total & & $\mathrm{P}<0.001$ \\
\hline Elementary & $112.00 \pm 17.12$ & \\
\hline Guidance school & $119.24 \pm 12.09$ & \\
\hline High school & $122.60 \pm 10.06$ & \\
\hline Associate's degree & $125.80 \pm 8.58$ & \\
\hline Bachelor's degree or higher & $128.15 \pm 8.27$ & \\
\hline
\end{tabular}

levels of education and income and those who had more children more believe that a child must work (13).

In the recent study findings demonstrate that parents with higher education levels, had more negative attitudes toward child abuse and education was the only characteristic that had a significant relationship with the all types of child abuse. Consistent with these results, also findings of a study by Qasem et al. (1998) showed that parents who had the higher education levels had fewer tendencies to physically discipline of children (14). As well as results of Park's study (2001) revealed mothers who had a low educational level were more likely agreed with physical child abuse and more likely to have an opinion that the reason of child abuse is parents' love for their children (7). The reason for this influence is that the fundamentals of the attitudes are related to individuals' personality, characteristics of the family and some of the cultural, social and economic impacts (5) and schools, colleges and universities are among society's major agents of socializations (15) and therefore attitudes are influenced by individual's education level.

The study showed that participants, who were single parent and take care of their children without their spouse, had more positive attitude towards neglect; maybe because of that absence of a parent means less care and supervision for children. Being single parent causes a parent take responsibility all of the parents' functions and tasks. This lead to responsibility over load in parents. The stress of single parenting destroys parents' psychological healthy and parenting effectiveness and makes conflict in parenting (16). The risk of mental health problems, physical and injury in children who live in single-parent families are more than two-parent families (17).

The finding of this study indicated that parents who had fewer children, had more negative attitude to physical child abuse. Although this result was significant only 
Table 4. Post Hoc Test to Determine the Significant Difference Among Means of Educational Groups ${ }^{\mathrm{a}, \mathrm{b}}$

\begin{tabular}{|c|c|c|c|}
\hline Attitude Toward Child Abuse (Comparison Groups) & Mean Difference & 95\% Confidence Interval of Mean Differenc & PValue \\
\hline \multicolumn{4}{|l|}{ Physical } \\
\hline Elementary-guidance school & 1.73 & $-1.38-4.85$ & 0.546 \\
\hline Elementary-high school & 3.72 & $0.98-6.47$ & 0.002 \\
\hline guidance school-high school & 1.99 & $-0.10-4.08$ & 0.071 \\
\hline Elementary-associate's degree & 5.74 & $2.46-9.04$ & $<0.001$ \\
\hline Elementary-bachelor's degree or higher & 6.26 & $3.26-9.26$ & $<0.001$ \\
\hline Guidance school-associate's degree & 4.01 & $1.24-6.78$ & 0.001 \\
\hline Guidance school-bachelor's degree or higher & 4.52 & $2.11-6.94$ & $<0.001$ \\
\hline High school-associate's degree & 2.02 & $-0.32-4.37$ & 0.128 \\
\hline Associate's degree-bachelor's degree or higher & 0.513 & $-2.13-3.15$ & 0.984 \\
\hline High school-bachelor's degree or higher & 2.53 & $0.62-4.45$ & 0.003 \\
\hline \multicolumn{4}{|l|}{ Emotional } \\
\hline Elementary-high school & 3.04 & $0.82-5.26$ & 0.002 \\
\hline Elementary-guidance school & 2.11 & $-0.40-4.64$ & 0.147 \\
\hline Guidance school-high school & 0.92 & $-0.72 \cdot 2.62$ & 0.565 \\
\hline Guidance school-associate's degree & 2.10 & $-0.13-4.35$ & 0.076 \\
\hline Elementary-associate's degree & 4.22 & $1.56-6.89$ & $<0.001$ \\
\hline High school-associate's degree & 1.18 & $-0.71-3.08$ & 0.429 \\
\hline High school-bachelor's degree or higher & 1.43 & $-0.11-2.99$ & 0.084 \\
\hline Associate's degree-bachelor's degree or higher & 0.25 & $-1.88-2.39$ & 0.997 \\
\hline Elementary-bachelor's degree or higher & 4.48 & $2.05-6.91$ & $<0.001$ \\
\hline Guidance school-bachelor's degree or higher & 2.36 & $0.41-4.32$ & 0.009 \\
\hline \multicolumn{4}{|l|}{ Neglect } \\
\hline Elementary-guidance school & 3.44 & $0.95 \cdot 5.93$ & 0.002 \\
\hline Guidance school-high school & 0.26 & $-1.43-1.93$ & 0.993 \\
\hline Guidance school-associate's degree & 0.46 & $-1.74-2.68$ & 0.978 \\
\hline Guidance school-bachelor's degree or higher & 1.03 & $-0.89-2.97$ & 0.580 \\
\hline Elementary-high school & 3.18 & $0.99-5.37$ & 0.001 \\
\hline High school-associate's degree & 0.73 & $-1.14-2.60$ & 0.822 \\
\hline High school-bachelor's degree or higher & 1.30 & $-0.23-2.83$ & 0.140 \\
\hline Elementary-associate's degree & 3.91 & $1.28-6.54$ & 0.001 \\
\hline Elementary-bachelor's degree or higher & 4.48 & $2.08-6.88$ & $<0.001$ \\
\hline Associate's degree-bachelor's degree or higher & 0.56 & $-1.54-2.68$ & 0.947 \\
\hline \multicolumn{4}{|l|}{ Total } \\
\hline Elementary-guidance school & 7.23 & $0.69-13.78$ & 0.022 \\
\hline Elementary-high school & 10.60 & $4.83-16.37$ & $<0.001$ \\
\hline Elementary-associate's degree & 13.79 & $6.89-20.71$ & $<0.001$ \\
\hline Elementary-bachelor's degree or higher & 16.14 & $9.84-22.45$ & $<0.001$ \\
\hline Guidance school-high school & 3.36 & $-1.03-7.76$ & 0.223 \\
\hline High school-associate’s degree & 3.19 & $-1.73-8.12$ & 0.389 \\
\hline Guidance school-associate's degree & 6.55 & $0.74-12.37$ & 0.018 \\
\hline Guidance school-bachelor's degree or higher & 8.90 & $3.83-13.99$ & $<0.001$ \\
\hline High school-bachelor's degree or higher & 5.54 & $1.51-9.57$ & 0.002 \\
\hline Associate's degree-bachelor's degree or higher & 2.35 & $-3.19-7.89$ & 0.773 \\
\hline
\end{tabular}

${ }^{\mathrm{a}}$ Post hoc test: Tukey.

$\mathrm{b}_{\mathrm{P}}<0.05$

among the one-child and two-child, but the populous family is risk factor for child abuse $(18,19)$. Less crowded family makes the family financial and emotional resources be di- vided among fewer individuals, and children benefit from more resources.

The present research also confirmed that parents who 
had a better economic situation had the more negative attitude toward neglect as a type of child abuse. Also in the study of Nuhu and Nuhu there was significant relationship between parents' attitude toward child abuse with their income and poor parents had more positive attitude toward child abuse (13). Family poverty is an important factor in child abuse occurrence and numerous studies have shown that child abuse often happened in poor families (20-23).

It seems a number of parents do not assume some of the behaviors as a kind of child abuse; because a considerable number of parents were agreed with threatening children to different kinds of punishment as a way to punish them. As well as a considerable number of parents agreed that children must be full obedience of their parents' orders. In the study of Agha Bakhshi et al. it was mentioned that $50 \%$ of mothers considered the term of child abuse (only) include severe beatings the children (12). Considering that in the other items, the majority of parents were against child abuse, it can be concluded that the reason for most parents agreement with these two item, was lack of enough information about the effects of these behaviors on children. This findings represent the necessity continuous education to the families and giving useful information about parenting style, the effects of emotional and psychological child abuse and neglect and nature of violent behaviors such as threatening the children and authoritarian parenting; because it was shown that unfavorable attitudes of parents, such as a maternal belief in rigid discipline are associated with more undesirable behavior with children (24).

In conclusion, this study showed that parents had negative attitude toward child abuse and their attitude was affected by their educational and economical status and being single-parents or two-parents. In particular, the level of education that is relevant with parents' attitude toward all types of child abuse. Thus providing conditions for individuals to access high education levels requires special attention.

Hence, the poor parents, single parents, or who that have lower education levels are prepared to child abuse. The government and social institutions should pay attention to such parents to prevent of child abuse.

\section{Acknowledgments}

Researchers are grateful to the respectable parents who agreed to participate in this study as well as to the research vice-chancellor of Tabriz University of Medical Sciences who provided financial support for this study.

\section{Footnotes}

Authors' Contribution: Study concept and design, Maliheh Asadollahi, Mahnaz Jabraeili, and Marzieh Hallaj; data collection, Marzieh Hallaj; analysis and interpretation of data, Mohammad Asghari Jafarabadi; drafting of the manuscript, Marzieh Hallaj; study supervision, Maliheh Asadollahi and Mahnaz Jabraeili.

Funding/Support: This article is taken from the master of nursing thesis with No. 395 adopted on 2013/07/06 and has been done with the financial support by the research vicechancellor of Tabriz University of Medical Sciences.

\section{References}

1. Irvanian A, Seidzade Sani M, Zade Naeini M, Javanmard B, Malju M. child abuse : From etiology to reply. 1st. Tehran: Khorsandi; 2010.

2. American Academy of Pediatrics, Stirling J Jr, Committee on Child Abuse and Neglect and Section on Adoption and Foster Care, et al. Understanding the behavioral and emotional consequences of child abuse. Pediatrics. 2008;122(3):667-73. doi: 10.1542/peds.20081885. [PubMed: 18762538].

3. Alink LR, Cicchetti D, Kim J, Rogosch FA. Longitudinal associations among child maltreatment, social functioning, and cortisol regulation. Dev Psychol. 2012;48(1):224-36. doi: 10.1037/a0024892. [PubMed: 21823793].

4. Altmann TK. Attitude: a concept analysis. Nurs Forum. 2008;43(3):14450. doi: 10.1111/j.1744-6198.2008.00106.x. [PubMed: 18715347].

5. Drod E, Pokorski M. Parental attitudes and social competence in adolescents. J Physiol Pharma. 2007;58(5):175-84.

6. Vittrup B, Holden GW, Buck J. Attitudes predict the use of physical punishment: a prospective study of the emergence of disciplinary practices. Pediatrics. 2006;117(6):2055-64. doi: 10.1542/peds.20052204. [PubMed: 16740848].

7. Park MS. The factors of child physical abuse in Korean immigrant families. Child Abuse and Neglect. 2001;25(7):945-58. doi: 10.1016/s01452134(01)00248-4. [PubMed: 11523870].

8. Jackson S, Thompson RA, Christiansen EH, Colman RA, Wyatt J, Buckendahl CWC, et al. Predicting abuse-prone parental attitudes and discipline practices in a nationally representative sample. Child Abuse and Neglect. 1999;23(1):15-29. doi: 10.1016/s0145-2134(98)001082. [PubMed: 10075190].

9. Bower-Russa ME, Knutson JF, Winebarger A. Disciplinary history, adult disciplinary attitudes, and risk for abusive parenting. J Community Psychology. 2001;29(3):219-40. doi:10.1002/jcop.1015.abs.

10. Ateah CA, Durrant JE. Maternal use of physical punishment in response to child misbehavior: implications for child abuse prevention. Child Abuse Negl. 2005;29(2):169-85. doi: 10.1016/j.chiabu.2004.10.010. [PubMed: 15734182].

11. Jadid Milani M, Soheil Arshadi F, Asadi Noghabi A. Text book of community health nursing. 2nd. Tehran: Andisheye rafie; 2006.

12. Agha Bakhshi H, Harir Chi M, Janghravi F. Survey on mothers's knowledge, attitude and practice about child abuse. Social Work 2005;5(3):76-85.

13. Nuhu FT, Nuhu ST. Opinions and attitudes of some parents in Ilorin, north-central Nigeria, towards child abuse and neglect. South African Journal of Psychiatry. 2010;16(1)

14. Qasem FS, Mustafa AA, Kazem NA, Shah NM. Attitudes of Kuwaiti parents toward physical punishment of children. Child Abuse and Neglect. 1998;22(12):1189-202. doi: 10.1016/s0145-2134(98)00097-0. [PubMed: 9871782]. 
15. Schein EH. Attitude Change During Management Education. Administrative Science Quarterly. 1967;11(4):601-28. doi:10.2307/2391078.

16. Brown SL. Family structure and child well-being: The significance of parental cohabitation. J.Marriage Fam. 2004;66(2):351-67. doi: 10.1111/j.1741-3737.2004.00025.x.

17. Weitoft GR, Hjern A, Haglund B, Rosén M. Mortality, severe morbidity, and injury in children living with single parents in Sweden: a population-based study. The Lancet. 2003;361(9354):289-95. doi: 10.1016/s0140-6736(03)12324-0.

18. Dubowitz H, Kim J, Black MM, Weisbart C, Semiatin J, Magder LS Identifying children at high risk for a child maltreatment report Child Abuse Negl. 2011;35(2):96-104. doi: 10.1016/j.chiabu.2010.09.003. [PubMed: 21376396].

19. Alyahri A, Goodman R. Harsh corporal punishment of Yemeni children: occurrence, type and associations. Child Abuse Negl. 2008;32(8):766-73. doi: 10.1016/j.chiabu.2008.01.001. [PubMed 18657859].

20. Abdullah MA, Basharat Z, Lodhi O, Wazir MH, Khan HT, Sattar NY, et al. A qualitative exploration of Pakistan's street children, as a consequence of the poverty-disease cycle. Infect Dis Poverty. 2014;3(1):11. doi: 10.1186/2049-9957-3-11. [PubMed: 24661542].

21. Eckenrode J, Smith EG, McCarthy ME, Dineen M. Income inequality and child maltreatment in the United States. Pediatrics. 2014;133(3):454-61. doi: 10.1542/peds.2013-1707. [PubMed: 24515511].

22. Guterman NB, Lee Y. The role of fathers in risk for physical child abuse and neglect: possible pathways and unanswered questions. Child Maltreat. 2005;10(2):136-49. doi: 10.1177/1077559505274623. [PubMed: 15798009].

23. Slack KS. Understanding the Risks of Child Neglect: An Exploration of Poverty and Parenting Characteristics. Child Maltreatment. 2004;9(4):395-408. doi: 10.1177/1077559504269193. [PubMed: 15538038].

24. Schuler ME, Nair P, Black MM. Ongoing maternal drug use, parenting attitudes, and a home intervention: effects on mother-child interaction at 18 months. JDev Behav Pediatr. 2002;23(2):87-94. [PubMed: 11943970] 